\title{
Assessment of Wastewater Reuse Effects on Nutrient Loads from Paddy Field Using Field-Scale Water Quality Model
}

\author{
Sang Min Kim • Sang June Im • Seung Woo Park • \\ Jeong Jae Lee • Brian L. Benham • Tae Il Jang
}

Published online: 29 April 2008

(C) Springer Science + Business Media B.V. 2008

\section{Erratum to: Environmental Modelling \& Assessment}

\section{DOI 10.1007/s10666-007-9093-7}

The affiliation of first author, Sang Min Kim, has changed recently.

The new affiliation is:

Department of Agricultural Engineering,

Institute of Agriculture and Life Science,

Gyeongsang National University,

Jinju 660-701, Republic of Korea;

The article was published in Volume 13 Issue 2, pp. 305-313.

The online version of the original article can be found at: http://dx.doi.org/10.1007/s10666-007-9093-7.

\section{S. M. Kim}

Department of Agricultural Engineering,

Institute of Agriculture and Life Science,

Gyeongsang National University,

Jinju 660-701, Republic of Korea

\section{S. J. Im $(\bowtie)$}

Department of Forest Science, Seoul National University,

Seoul 151-742, Republic of Korea

e-mail: junie@snu.ac.kr

S. W. Park $\cdot$ J. J. Lee $\cdot$ T. I. Jang

Department of Rural Engineering, Seoul National University,

Seoul 151-742, Republic of Korea

B. L. Benham

Biological Systems Engineering Department,

Virginia Polytechnic Institute and State University,

Blacksburg, VA 24061, USA 